\title{
Noise Distribution of the Internal Combustion Engine
}

\section{Guo Ya Ru ${ }^{1, a}$, Liu Yan², b, Xiaopai Zhang ${ }^{3, c}$, Xiaojuan Zhang ${ }^{4, ~ d, ~ C h a n g b i n ~}$ Zhang ${ }^{5, e}$}

\author{
${ }^{1}$ Institute of Transportation Engineering, Dalian Jiaotong University, Dalian, 116028, China \\ ${ }^{2}$ Institute of Transportation Engineering, Dalian Jiaotong University, Dalian, 116028, China \\ ${ }^{3}$ Institute of Transportation Engineering, Dalian Jiaotong University, Dalian, 116028, China \\ ${ }^{4}$ Department of Mechanical Engineering, Dalian Institute of Science and Technology, Dalian \\ 116052 China
}

${ }^{5}$ Department of Educational Administration, Dalian Jiaotong University, Dalian, 116028, China

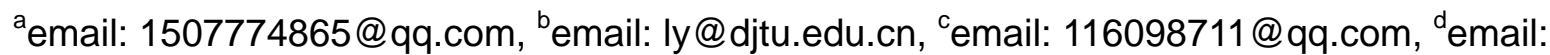
405994107@qq.com, eemail: 12352477@qq.com

Keywords: diesel engine; noise; vibration; spectrum; test

\begin{abstract}
Use noise and vibration measurement and analysis system for diesel engine noise and vibration testing and spectrum analysis.Draws the following distribution:Engine noise level mainly concentrated in $400 \mathrm{~Hz}-2000 \mathrm{~Hz}$ in the normal operating conditions, the noise value of each measuring point appear a peak at about $800 \mathrm{~Hz}$.Intake noise is important source of noise and the noise values of the point 9 (near the intake port) are greatest in any condition.Load is constant, the sound pressure level increases as the speed increases, and the rate of increase become small when speed is high. The vibration acceleration of air intake increases sharply and appear a peak at $400 \mathrm{~Hz}$, causing structural resonance.Results of this research have some reference value for vibration and noise reduction design of diesel engine.
\end{abstract}

\section{The test of engine noise and vibration}

\section{Test equipment and acoustic environment}

This test uses HEAD acoustics noise and vibration measurement and analysis system.The acoustic environment is lead to the exhaust pipe outside, do not consider the exhaust noise for whole machine test, the internal combustion engine use the water-cooled means and the air filter is not installed, so measured is the diesel whole machine surface radiation noise [3].

2 Test objects and test point arrangement

(1)Test objects: a single vertical direct injection four-stroke marine diesel engines, the technical parameters of the diesel engine as shown in table 1. The internal combustion engine is directly connected to the dynamometer to measure its speed and power. Figure 1 is the test site picture.

Table 1 The technical parameters of diesel

\begin{tabular}{cccc}
\hline Piston stroke $(\mathrm{mm})$ & 140 & Piston displacement & $8 \mathrm{~L}$ \\
\hline Rated speed $(\mathrm{r} / \mathrm{min})$ & 1500 & Firing order & $1-3-4-2$ \\
\hline Dimensions $(\mathrm{mm})$ & $157 \times 94 \times 130$ & Number of cylinders & 4 \\
\hline cooling method & Closed circulation water cooling & Weight $(\mathrm{Kg})$ & 950 \\
\hline
\end{tabular}

(2)test point arrangement: noise point distribution in accordance with national standards, "reciprocating internal combustion emitted airborne noise - engineering method and simple method" (GB1859-2000) requires nine layout method,by the dimensions of the measuring points are arranged as shown in Figure 1[5].Vibration distribution points should be measured on a solid body or structural point of application value in accordance with the relevant standards, three points were arranged combined with the actual, namely, the position of the upper portion of the diesel engine air intake, diesel central box, diesel underframe location. 


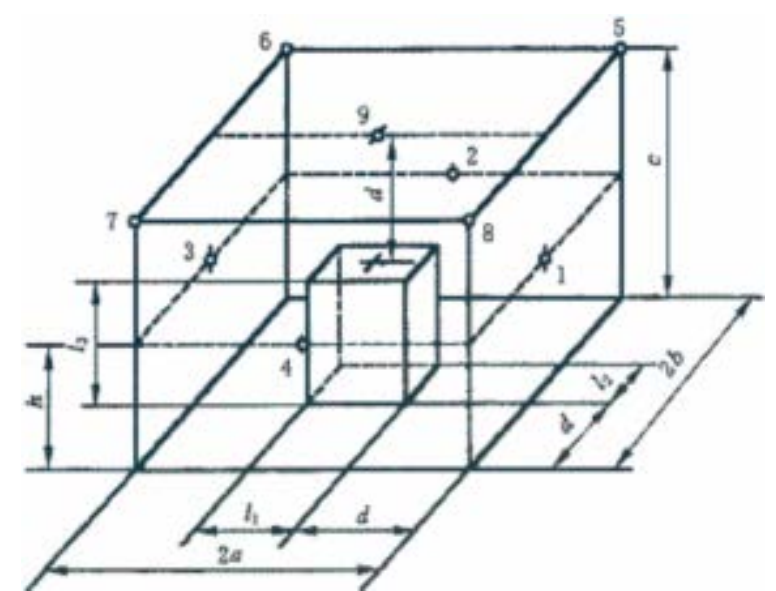

Fig 1 noise measuring point layout

\section{Test conditions}

The operation of the diesel engine to a predetermined condition, engine oil temperature, water temperature rises to the normal operating temperature,stabilized at the calibration conditions to test.During the test sampling frequency is $24000 \mathrm{~Hz}$. Test conditions shown in table 2, each condition tested twice, each time was 10s, temperature 20

${ }^{\circ} \mathrm{C}$, humidity of $55 \%$.

Table 2 Test conditions

\begin{tabular}{|c|c|c|c|c|c|}
\hline Speed / (r / min) & 1000 & 1200 & 1300 & 1400 & 1500 \\
\hline Load (\%) & $\begin{array}{l}\text { 100、75、50、 } \\
\text { 30、 Unloaded }\end{array}$ & $\begin{array}{r}100 、 75 \\
50 、 30\end{array}$ & 100 & $\begin{array}{c}100 、 75 、 \\
50 、 30\end{array}$ & $\begin{array}{r}100 、 75 \\
50 、 30\end{array}$ \\
\hline
\end{tabular}

\section{Test results and analysis}

1 Analysis of noise spectral characteristics

The noise spectrum picture of each measuring point at speed $1000 \mathrm{r} / \mathrm{min}$, 30\% load as shown in figure2.

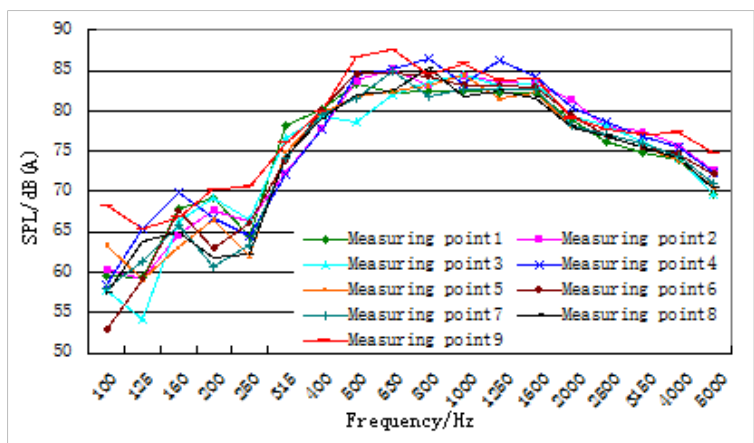

Fig 2 The spectrum of each measuring point at 1000r / min, at 30\% load

Analysis from figure 2 that the noise mainly concentrated on $400 \mathrm{~Hz}-2000 \mathrm{~Hz}$, the noise value of each measuring point appear a peak at about $800 \mathrm{~Hz}$.Noise of the measuring point 9 position (nearby the intake and exhaust port) is maximum and it is intake noise, when the air flow at high speed flow through the inlet valve flow cross-section to form a vortex, generates high-frequency noise.Thus informed, the intake noise is an important source of noise, noise reduction measures should be considered and design good performance intake silencer.In addition to measuring point 9 , noise level of the measuring point 4 is high, the reason is the measuring point 4 near the cylinder, the combustion noise is relatively large. The noise value of the measuring point 1 (pulley side) has been greater at $1250 \mathrm{~Hz}$ later, the noise of the side mainly is the mechanical noise produced by gears, in addition to ,when the diesel engine at high speed and high load operation,the noise radiated from the crankshaft causing pulley and timing gear cover strong vibrations has a greater contribution[4]. 
2 Speed on the influence of noise

From the above analysis,the noise level of measuring point 4 and measuring point 9 is higher compared with the other measuring points, is the main source of noise, so focuses on measuring point 4 and measuring point 9 .

Measuring point 9 diesel engine noise trend along with the change of speed as shown in figure 3.

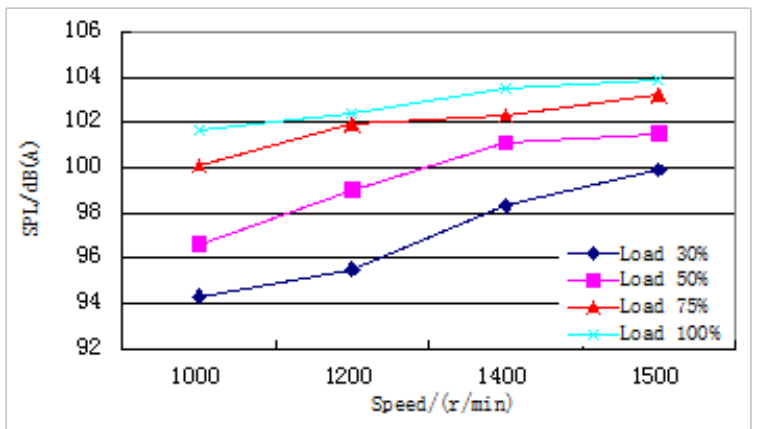

Fig 3 Sound pressure level along with the change of speed

It can be seen from figure 3, when the load is constant, the sound pressure level increases with increasing speed,and the rate of increase becomes smaller when the speed is high.Diesel engine load is $30 \%$, the noise value increases $6 \mathrm{~dB}$ (A) when the speed increased from $1000 \mathrm{r} / \mathrm{min}$ to $1500 \mathrm{r} /$ min,speed rising 100r / min, the sound pressure level increased by approximately $2 \mathrm{~dB}(\mathrm{~A})$.

3 Load on the influence of noise

Measuring point 4 diesel engine noise trend along with the change of load as shown in figure 4.

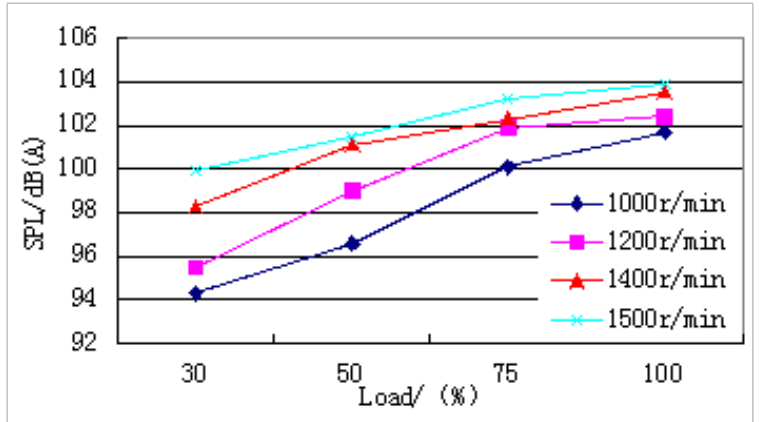

Fig 4 sound pressure level along with the change of load

It can be seen from figure 4, when the speed is constant, the sound pressure level increases with increasing load,and the rate of increase becomes smaller when the load is high.Diesel engine speed is $1000 \mathrm{r} / \mathrm{min}$, the noise value increases $6 \mathrm{~dB}(\mathrm{~A})$ when the load increased from $30 \%$ to $75 \%$ and the noise value increases $1 \mathrm{~dB}$ (A) when the load increased from $75 \%$ to $100 \%$.With the load increases, the heat release per cycle increased, the maximum combustion pressure and pressure rise rate increased, which makes combustion noise enhancement, but with the load increases, the combustion chamber wall temperature rise, the gap of the cylinder and the piston is reduced , which in turn makes the combustion noise mitigation [1], so that the noise level increases slowed when the load increases to $75 \%$.

4 Analysis of vibration spectral characteristics

The vibration spectrum picture of three measuring points at speed $1500 \mathrm{r} / \mathrm{min}, 75 \%$ load as shown in figure5. 


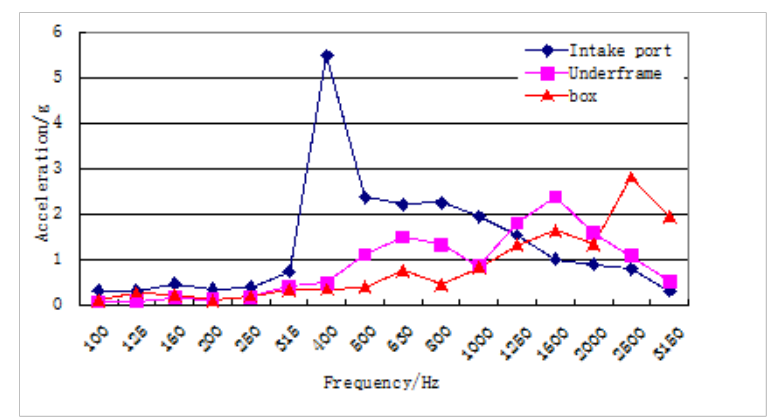

Fig 5 vibration spectrum

It can be seen from figure 5, at low frequencies, the vibration acceleration of three points are very low and inlet vibration acceleration increased dramatically and occurs a peak at $400 \mathrm{~Hz}$,this shows a structural resonance at $400 \mathrm{~Hz}$. The chassis and body vibration acceleration with the increase of the frequency increases for shock tendency,brace peaked at $1600 \mathrm{~Hz}$, while the cabinet peaked at $2500 \mathrm{~Hz}$.Compared with figure 2, noise level of measuring point 9 (near the air intake port) increase sharply at $400 \mathrm{~Hz}$, noise value is higher at $400 \mathrm{~Hz}-1600 \mathrm{~Hz}$, and the noise of other measuring points are mainly concentrated in the high-frequency, vibration rules of the three vibration points with the noise level rules is almost the same, showing that vibration is the main cause of noise[2].

Vibration spectrum of the cabinet at different speeds and 100\% load shown in figure 6.It can be seen from the figure, vibration acceleration at $400 \mathrm{~Hz}-3150 \mathrm{~Hz}$ frequency variation is more obvious, with the increase in the speed of the vibration acceleration increases and the higher the speed the greater the magnitude of the increase.The vibration acceleration increases $2.5 \mathrm{~g}$ when the speed increased from 1000r / min to $1500 \mathrm{r} / \mathrm{min}$ at the frequency of 2000,so speed greater impact on acceleration.

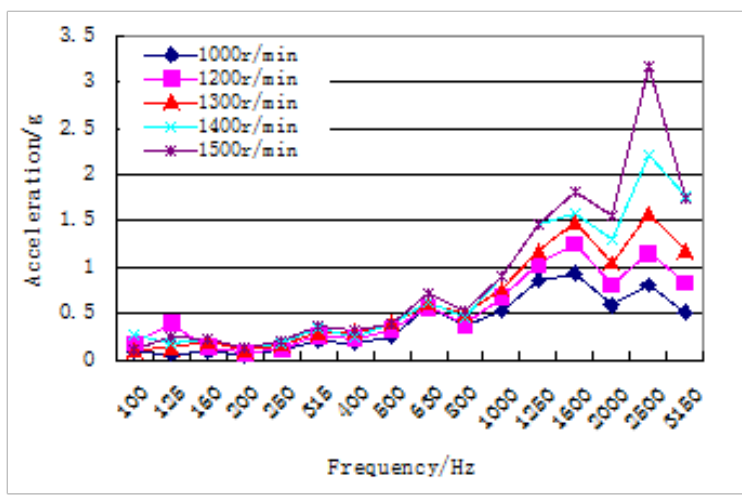

Fig 6 Vibration spectrum of the cabinet at different speeds and 100\% load

Vibration spectrum of the air intake port at different loads and speed 1000r/min shown in figure 7.It can be seen from the figure,the vibration spectrum increases with increasing load and frequency variation is more obvious at $400 \mathrm{~Hz}-3150 \mathrm{~Hz}$, The vibration acceleration increases $2.5 \mathrm{~g}$ when the load increased from unload to load $100 \%$ at the frequency of 2000.

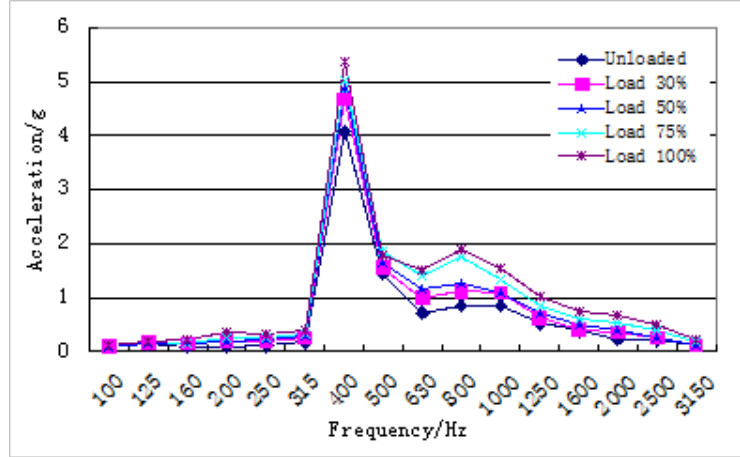

Fig 7 Vibration spectrum of the air intake port at different loads and speed 1000r/min 


\section{Conclusions}

Through the diesel engine noise and vibration tests under different conditions, the following conclusions can be drawn:

(1)Engine noise level mainly concentrated in $400 \mathrm{~Hz}-2000 \mathrm{~Hz}$ in the normal operating conditions, the noise value of each measuring point appear a peak at about $800 \mathrm{~Hz}$.

(2)Intake noise is important source of noise and the noise values of the point 9 (near the intake port) are greatest in any condition, so noise reduction measures should be considered design good performance intake silencer.

(3) When the load is constant, the sound pressure level increases with increasing speed,and the rate of increase becomes smaller when the speed is high.Diesel engine load is $30 \%$, the noise value increases $6 \mathrm{~dB}(\mathrm{~A})$ when the speed increased from 1000r / min to $1500 \mathrm{r} / \mathrm{min}$.

(4)when the speed is constant, the sound pressure level increases with increasing load,and the rate of increase becomes smaller when the load is high.Diesel engine speed is $1000 \mathrm{r} / \mathrm{min}$, the noise value increases $6 \mathrm{~dB}(\mathrm{~A})$ when the load increased from $30 \%$ to $75 \%$ and the noise value increases $1 \mathrm{~dB}(\mathrm{~A})$ when the load increased from $75 \%$ to $100 \%$.

(5)The chassis and body vibration acceleration with the increase of the frequency increases for shock tendency,brace peaked at $1600 \mathrm{~Hz}$, while the cabinet peaked at $2500 \mathrm{~Hz}$,inlet vibration acceleration increased dramatically and occurs a peak at $400 \mathrm{~Hz}$ and cause structural resonance, we should take measures to avoid the resonance frequency.Vibration regulation of three vibration points and sound level are basically the same, vibrations are the main cause of noise.

\section{References}

[1]Zhihua Zhang,Song Zhou. The Internal Combustion Engine Emissions and Noise Control [M]. Heilongjiang: Harbin Engineering University Press, 2008: 140-148.

[2]Yanting Wu,Weiping Yuan. Internal Combustion Engine Noise and Vibration Control [M] Beijing: Mechanical Industry Press, 2004.3.

[3]Fujiang Wang. Diesel Sound Quality Testing and Analysis of Objective Parameters [J] Noise and Vibration Control .2014,8.

[4]Gequn Shu,Haiqiao Wei.Combustion Noise Mechanism Under Transient Conditions of DI Diesel Engine [J] Combustion Science and Technology .2005,11 volume.

[5]National standards, "Reciprocating Internal Combustion Emitted Airborne Noise - Engineering Method and Simple Method" (GB1859-2000).[S].2000. 